\title{
Progeroid syndrome, Petty type
}

INSERM

\section{Source}

INSERM. (1999). Orphanet: an online rare disease and orphan drug data base. Progeroid syndrome, Petty type. ORPHA:2963

Progeroid syndrome, Petty type is a rare premature aging syndrome characterized by pre-and postnatal growth retardation, a cong enital premature-ag ed appearance with distinctive craniofacial dysmorphism (wide calvaria with large open anterior fontanel and wide metopic suture, broad forehead, small face, micrognathia), markedly diminished subcutaneous fat, cutis laxa and wrinkled skin, without delay in psychomotor development. Scant, brittle hair, hypoplastic nails and delayed, abnormal dentition, as well as hypoplastic distal phalanges, umbilical hernia and eye abnormalities (myopia/hyperopia, strabismus), are also commonly associated. 